\title{
Dynamic Characteristic Simulation Analysis of High Speed Milling Motorized Spindle
}

\author{
Fei Zhang* and Jian Wei \\ Jinhai Road 2360\#, Pudong District, Shanghai, China, 201209 \\ ${ }^{*}$ Corresponding author
}

\begin{abstract}
The machining quality and cutting ability of the machine depends largely on the dynamic characteristics of the machine tool spindle bearing system. In this paper, the author will use the ANSYS finite element software to analyze the dynamic characteristics of the high speed milling motorized spindle, so as to verify the rationality of the structure design of the spindle.
\end{abstract}

Keywords-motorized spindle; dynamic analysis; modal analysis

\section{INTRODUCTION}

With the rapid development of modern laser and micro electronic equipment, ultra high speed and ultra precision machining technology has become the development direction of future product processing. In the airline industry, defense industry and other fields, ultra high speed and ultra precision processing equipment has been widely used. The dynamic characteristics of the machining quality and cutting ability of the machine depends largely on machine tool spindle bearing system. In the manufacturing process, high speed electric spindle unit is directly powered and parts processing, installation tool or work piece in the front the spindle, directly involved in machining. Machining accuracy of machine tools, the surface roughness and productivity effects are direct. When the cutting process in the larger vibration, will make the tool wear or damage, will increase the spindle bearings and machine tool guide rail to bear the dynamic load, thereby reducing its life and accuracy. In this paper, the ANSYS finite element software is used to analyze the dynamic characteristics of the motorized spindle unit, so as to verify the rationality of the structure design.

\section{BASIC DESign PARAmeters OF High SpeEd Milling MOTORIZED SPINDLE}

The basic design parameters of high speed milling motorized spindle are shown in Table 1 . The design structure schematic of the high-speed milling spindle is shown in Figure 1.

The motor rotor 11 is connected with the main shaft body 1 through interference fit. The main body part 1 by around two sets of angular contact ceramic ball bearing 10,13 support group, the two groups before and after the bearing on the overall for back-to-back mounting, front bearing axial fixation group 10 , to ensure the machining precision milling spindle bearing in the axial direction; after 13 floating, can trace moving to thermal elongation compensation main shaft work the. The motor stator and the water jacket 12 clearance, and through a trough of a pin to circumferential fixation, ensure stability of motor magnetic field. The water jacket 6 is provided with a spiral groove, cooling water is injected into the loop through the heat loss of motor. The bearing group is lubricated by oil and gas, and the lubricating oil is injected directly into the bearing ball body to realize the lubrication of the bearing. In order to meet the requirements of high-speed processing, tool selection interface HSK40 taper shank 1:10. The main body 1 is a hollow shaft, is mounted inside the HSK system produced by OTT company 14 broach.

TABLE I. MAIN DESIGN PARAMETERS OF MOTORIZED SPINDLE

\begin{tabular}{|c|c|c|}
\hline $\mathrm{Nr}$ & $\begin{array}{l}\text { Technical index } \\
\text { name }\end{array}$ & Technical index value \\
\hline 1 & Sleeve diameter & $170 \mathrm{~mm}$ \\
\hline 2 & Maximum speed & 18000rpm \\
\hline 3 & Rated speed & 10000rpm \\
\hline 4 & Rated power & $45 \mathrm{~kW}$ \\
\hline 5 & Tool system & HSK 63 \\
\hline 6 & $\begin{array}{l}\text { Tool cooling } \\
\text { mode }\end{array}$ & Central cooling \\
\hline 7 & $\begin{array}{l}\text { Rotation } \\
\text { precision }\end{array}$ & $\begin{array}{l}\text { End runout }<2 \mu \mathrm{m}, \\
\text { Radial runout }<3 \mu \mathrm{m}\end{array}$ \\
\hline 8 & temperature rise & $\begin{array}{c}\text { Maximum speed to thermal } \\
\text { equilibrium state, Front bearing } \\
\text { peripheral }<25^{\circ} \mathrm{C} \text {, Outer of the } \\
\text { sleeve }<20^{\circ} \mathrm{C}\end{array}$ \\
\hline 9 & Vibration & $\begin{array}{l}\text { At the maximum speed, the } \\
\text { vibration speed }<0.4 \mathrm{~mm} / \mathrm{s}\end{array}$ \\
\hline 10 & Noise & $<70-75 \mathrm{~dB}$ \\
\hline 11 & $\begin{array}{l}\text { Static clamping } \\
\text { force }\end{array}$ & $18 \mathrm{kN}$ \\
\hline 12 & Life & $>8000$ Working hours \\
\hline
\end{tabular}

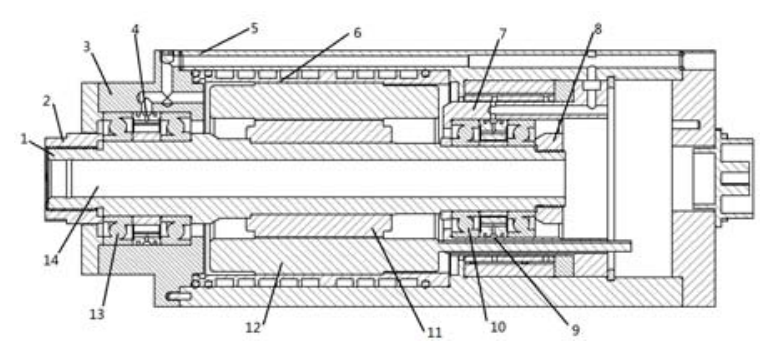

FIGURE I. SCHEMATIC DIAGRAM OF ELECTRIC SPINDLE STRUCTURE IN HIGH SPEED MILLING 
1 main body 2 front locking nut 3 front bearing seat 4 nozzle 5 shell jacket 6 Water jacket 7 bearing seat 8 lock nut 9 nozzle 10 The rear bearing group 11 Motor rotor 14 group of 13 front bearing system broach.

\section{MODAL ANALYSIS OF MOTORIZED SPINDLE}

Modal analysis is a new method to study the dynamic characteristics of structures, and it is the application of the system identification method in the field of Engineering Vibration [1]. Mode is the natural vibration characteristics of the mechanical structure, each mode has a specific natural frequency, damping ratio and modal vibration mode. These modal parameters can be obtained by the calculation or test analysis, such a calculation or test analysis process is called modal analysis.

\section{A. ANSYS Modal Analysis}

Modal analysis using ANSYS integrated module Workbbench. The natural frequency of the model is affected by the stress state of the structure. Firstly, the dynamic structure of the spindle assembly is analyzed, the assembly file is imported into ANSYS, loaded and solved. The results obtained are used as the loading condition of modal analysis, and the extended mode is solved again. As shown in Figure 2 for the modal analysis process, the results of the modal analysis include: natural frequency, extended mode and the corresponding stress distribution, can be used in color image, vector and list display [2].

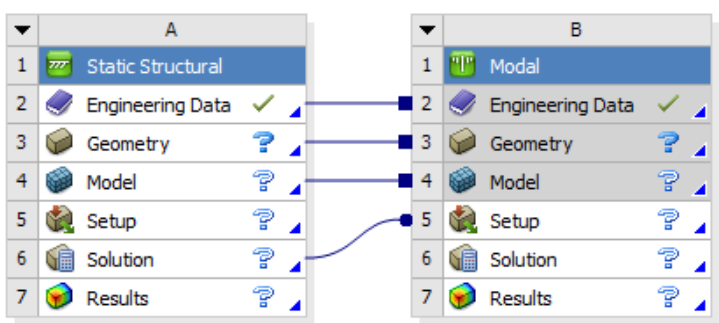

FIGURE II. MODAL ANALYSIS OF SPINDLE BODY

\section{B. Finite Element Modeling and Mesh Generation}

In order to carry on the dynamic simulation analysis of the spindle unit accurately and effectively, the finite element method is used to carry out the 3D modeling. When you need to put the whole modeling model of spindle unit: the following simplified motor rotor, bearing and a locking sleeve, a locking sleeve, encoder and spindle body is in interference fit with the shaft core is simplified as excluded together, equivalent to the material density of shaft, when modeling by the integration process will be simplified; angular contact ball bearings the elastic support, at the intersection of the pivot position in the contact line and axis; that only has the bearing radial stiffness, with angular stiffness, so the support is further simplified into a radial compression spring mass unit; each bearing in the circumferential direction of the equivalent distribution of four springs, neglecting the effect of bearing load and speed of the bearing stiffness the line of sight of the stiffness for a fixed constant.

According to the principle of simplification, the finite element model of the motorized spindle is divided according to the above unit selection, and the finite element mesh is obtained as shown in Figure 3. The model consists of 211957 units and 323010 nodes.

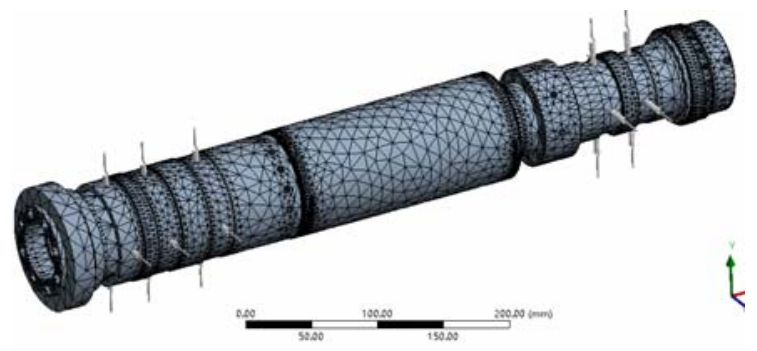

FIGURE III. GRID DIVISION OF ELECTRIC SPINDLE MODEL

\section{Finite Element Loading and Solving}

Bearing support for one end of the fixed end of the fixed end of the swimming, the former bearing for the fixed end, so the constraints of its full degree of freedom, after the bearing for the swimming ends, its axial swimming, its axial without restraint. At the same time, the model is applied to the gravity acceleration. As shown in Figure 4, the model of the motorized spindle is loaded to solve the structural analysis effect diagram after loading. Figure 4 shows the schematic diagram of the motorized spindle model loading, figure 5 for the solution of the effect diagram.

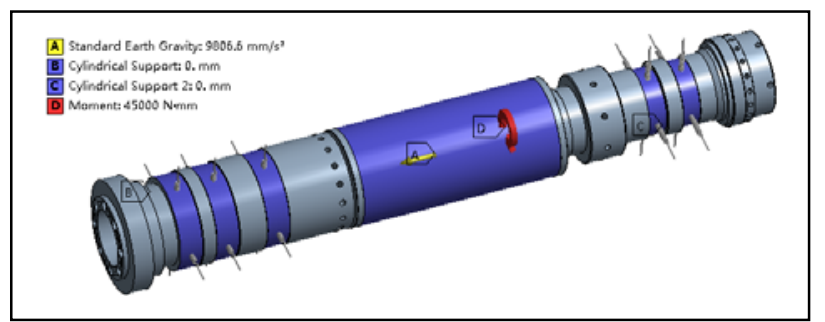

FIGURE IV. ELECTRIC SPINDLE MODEL LOAD

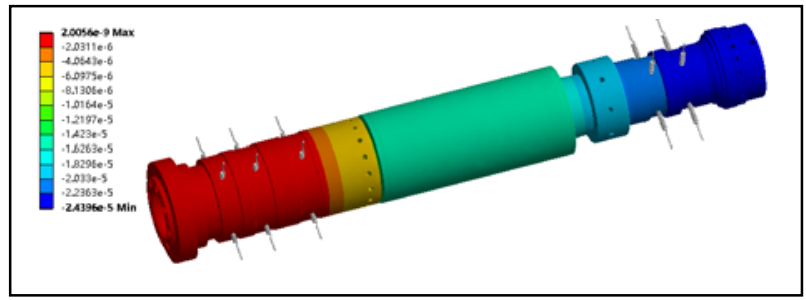

FIGURE V. AXIAL STRESS DEFORMATION DIAGRAM

Modal analysis using Subspace (subspace method) to carry out the modal extraction, after the calculation of the ANSYS operation, the electric spindle each order frequency $(\mathrm{Hz})$ and vibration mode as shown in table 2.

\section{Analysis of Critical Speed of Electric Spindle}

The critical speed of the traditional definition is the natural frequency of the spindle, spindle speed for general low speed, influence on the dynamic characteristics of the spindle is not large, so the definition of full compliance, of electric spindle, this method is not suitable, because the electric main shaft speed is generally higher, and therefore can not be ignore the 
effect of rotational speed on its dynamic characteristics. In the calculation of critical speed of spindle rotation, when the frequency of shaft and its natural frequency is equal to the shaft resonance, when damping is ignored, the theory on the amplitude tends to infinity, this happens will damage the spindle in the actual precision of the spindle shaft even main body, so the corresponding rotating shaft the frequency of rotation is called critical speed.

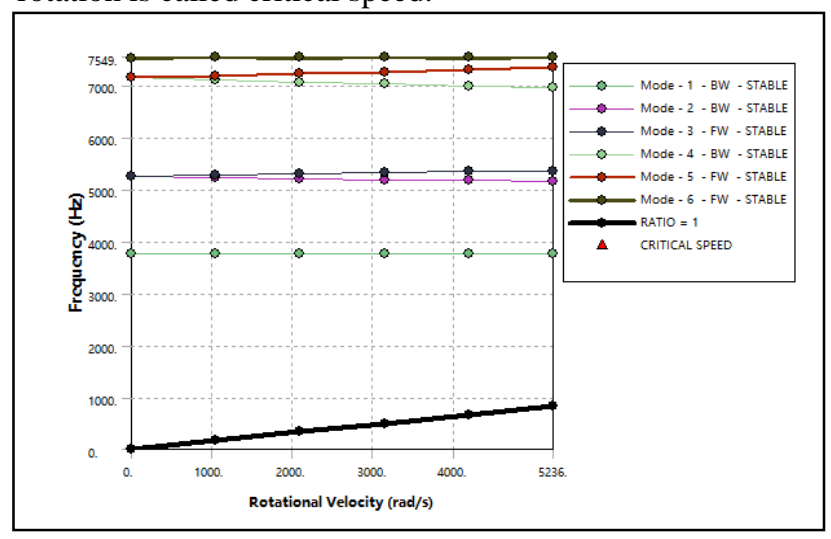

FIGURE VI. MODAL ANALYSIS CAMPBELL
As shown in Figure 6, the modal analysis of the resulting Campbell diagram, the horizontal coordinate for the speed, and the longitudinal coordinates for the frequency. From the graph, the critical speed of the spindle is far greater than the working speed, so the design is reasonable, can effectively avoid the resonance area.

\section{CONCLUSION}

In this paper, the finite element simulation software ANSYS is used to simulate the dynamic characteristics of high speed milling motorized spindle. The electric spindle unit model loading, edit boundary conditions, obtain vibration and vibration frequency of the spindle during high-speed operation, the critical speed analysis of spindle, which verified the structure meet the design requirements of spindle.

\section{REFERENCES}

[1] Sun Jingjing, Review of modal analysis methods for mechanical structures J. science and technology information , 2014 (3): 80-80

[2] Pu Guangyi, ANSYS Workbench basic tutorial and example explanation (Second Edition) [M]. Chinese water conservancy and Hydropower Press 2013.4

TABLE II. ELECTRIC SPINDLE FIRST SIXTH ORDER NATURAL FREQUENCY

\begin{tabular}{|c|c|c|c|c|c|c|}
\hline Point & 1 & 2 & 3 & 4 & 5 & 6 \\
\hline Mode & $0 . \mathrm{rad} / \mathrm{s}$ & $1047.2 \mathrm{rad} / \mathrm{s}$ & $2094.4 \mathrm{rad} / \mathrm{s}$ & $3141.6 \mathrm{rad} / \mathrm{s}$ & $4188.8 \mathrm{rad} / \mathrm{s}$ & $5236 . \mathrm{rad} / \mathrm{s}$ \\
\hline 1. & $3773 . \mathrm{Hz}$ & $3772.5 \mathrm{~Hz}$ & $3771.2 \mathrm{~Hz}$ & $3769.1 \mathrm{~Hz}$ & $3766 . \mathrm{Hz}$ & $3762.1 \mathrm{~Hz}$ \\
\hline 2. & $5249.8 \mathrm{~Hz}$ & $5230.9 \mathrm{~Hz}$ & $5210.3 \mathrm{~Hz}$ & $5190 . \mathrm{Hz}$ & $5170.2 \mathrm{~Hz}$ & $5150.7 \mathrm{~Hz}$ \\
\hline 3. & $5254.3 \mathrm{~Hz}$ & $5273.6 \mathrm{~Hz}$ & $5295.2 \mathrm{~Hz}$ & $5317.1 \mathrm{~Hz}$ & $5339.3 \mathrm{~Hz}$ & $5361.8 \mathrm{~Hz}$ \\
\hline 4. & $7147.6 \mathrm{~Hz}$ & $7110.1 \mathrm{~Hz}$ & $7071.4 \mathrm{~Hz}$ & $7032.8 \mathrm{~Hz}$ & $6994.5 \mathrm{~Hz}$ & $6956.4 \mathrm{~Hz}$ \\
\hline 5. & $7150.5 \mathrm{~Hz}$ & $7188.2 \mathrm{~Hz}$ & $7227.6 \mathrm{~Hz}$ & $7267.2 \mathrm{~Hz}$ & $7307 . \mathrm{Hz}$ & $7347 . \mathrm{Hz}$ \\
\hline 6. & $7536.4 \mathrm{~Hz}$ & $7536.9 \mathrm{~Hz}$ & $7538.4 \mathrm{~Hz}$ & $7540.9 \mathrm{~Hz}$ & $7544.4 \mathrm{~Hz}$ & $7549 . \mathrm{Hz}$ \\
\hline
\end{tabular}

